\title{
A Escola Uspiana de História: panorama das contribuições da história da historiografia para um tema clássico
}

The Escola Uspiana de História: an overview of the contributions from history of historiography to a classical theme

Aryana Lima Costa*

\section{Resumo}

Este artigo pretende analisar as obras que tratam do início da produção historiográfica do curso de história da Universidade de São Paulo. Para tanto, compreende fontes/obras bibliográficas que lançaram as bases para o que se convencionou chamar de "Escola Uspiana de História", bem como outras que problematizam os modos e/ou periodização sobre a incorporação de pressupostos da Escola dos Annales no Brasil. Por último, para fins de publicização, apresenta-se uma proposta de livro sobre história do Brasil encontrada na documentação de Fernand Braudel presente na Fondation Maison des Sciences de l'Homme.

Palavras-chave: memória; historiografia; Escola Uspiana de História.

\section{Abstract}

This article aims to analyze some of the production that has been written about the beginning of the historiographical production of the undergraduate History course at the University of São Paulo (USP). That will refer to documents and bibliographical works that set the basis for what has come to be understood as the Escola Uspiana de História, as well as to others which question the ways and periodization of the incorporation of the Annales School's contributions in Brazil. The article also presents the proposal for a book on the history of Brazil found in documents belonging to Fernand Braudel, located at the Fondation Maison des Sciences de L'Homme. Keywords: memory; historiography; Escola Uspiana de História.

\section{A HistóRIA DE UMA HISTORIOGRAFIA MONUMENTAL}

Em se tratando de apresentar a história dos cursos superiores de história no Brasil, desde que esse curso exista, fazer a história de qualquer um deles é

\footnotetext{
* Universidade do Estado do Rio Grande do Norte (UERN), Mossoró, RN, Brasil. aryanacosta@gmail. com. <https://orcid.org/0000-0003-0208-778X >
} 
plausível e justificável. Mas por uma memória acadêmica construída sobre a trajetória dessa disciplina no país, o recorte do curso de história da Universidade de São Paulo (USP) fundado em 1934 é um dos mais recorrentes, seja a partir da história da historiografia ou da trajetória das instituições universitárias.

Isso possivelmente ocorre porque esse é o primeiro curso universitário de história no país que teve continuidade até os dias atuais, conferindo-lhe o status de "pioneiro", "fundador", entre outros termos que demarcam sua presença na origem da profissionalização da nossa categoria. Na história do curso de história da USP ou da historiografia nacional invariavelmente faz-se menção à presença francesa, destacando-se que os professores franceses que vieram lecionar no curso pertenceriam à Escola dos Annales, assim como a figura de Fernand Braudel.

Estratégias como a mobilização de memórias sobre a competência desses professores e sua performance acadêmica são utilizadas para a construção, ou corroboração, de identidades e posicionamento de sujeitos no campo acadêmico da história. Isso possibilitou as bases para o que se convencionou chamar de "Escola Uspiana de História”. Há um conjunto de fontes que evidenciam a "cultura de memória acadêmica" que constrói lugares de memória para a historiografia nacional, como os vários depoimentos de ex-alunos e professores sobre esse período. A partir desses testemunhos, verifica-se que também as autoimagens e valores criados por nós mesmos sobre o que deve ser historiador podem determinar nossas ações. ${ }^{1}$ Não à toa e muito ironicamente, fazemos questão também de ter nossos pais fundadores e nossas genealogias às vezes definidos e valorizados tanto (ou mais) por suas virtudes quanto por seus trabalhos.

Nesse caso, as memórias e o comportamento rotinizado pertencente a ritos institucionais de determinado grupo de historiadores pintaram um lugar especial ocupado pelos professores franceses na fundação do que seria uma moderna historiografia na universidade nacional. Tal historiografia se originou de maneira diferenciada pela sua associação aos representantes de instituições francesas que vieram ministrar cursos na recém-criada Faculdade de Filosofia, Ciências e Letras (FFCL) da USP e que por suas práticas se distinguiam dos professores nativos, ocupantes das cadeiras de história da civilização brasileira e de etnografia Tupi-Guarani. Essa chave explicativa perdurou por algum tempo depois da partida dos professores franceses sob a forma de testemunhos, discursos, publicações (inclusive aquelas in memoriam) e rituais institucionais. Tais testemunhos ganham importância especial, pois nos trabalhos sobre a história dos cursos de graduação em História costumam ser 
um dos principais conjuntos de fontes aos quais se recorre para reconstituir a trajetória inicial desses cursos, sendo que algumas de suas impressões são incorporadas, com frequência, na narrativa sobre a evolução da produção historiográfica de tal instituição ou período, como o exemplo a seguir alusivo ao nosso recorte.

Eduardo d'Oliveira França foi instado a falar de sua experiência como ex-aluno do curso de geografia e história da USP em várias ocasiões comemorativas. Aluno do professor Braudel nos anos de 1935 a 1937, na cadeira de história da civilização, descreve sua aula com tremendo carinho na entrevista realizada em 1990, encontrada no Centro de Apoio à Pesquisa Histórica:

Mas o maior professor que conheci foi o grande historiador Fernand Braudel. Em sua aula o tempo passava sem que se percebesse. Empolgava a classe que ficava presa em um silêncio. Ele nos revelou a escola dos Annales, a existência do ensino secundário com o Malet Isaac, valorizava os compêndios. E escolhia os alunos - uns eram seus alunos e se interessava até pela vida particular, os outros não tinham interesse. Recomendava muito literatura. (França, 1990, grifo nosso)

Na fala à Sônia de Freitas, em 1990, França lembra que os professores franceses com os quais conviveu

tiveram um papel muito grande na modelagem e no estilo do que se destinava a ser um Centro de Estudos de História e de Geografia. Estávamos empenhados em um programa de renovação e de criação de uma Historiografia e de uma Geografia no padrão do que se professava lá fora. Sem conflitos, sem atrasos. (Freitas, 1992, p. 183)

A novidade continua sendo associada aos franceses e à atividade de seus herdeiros nos cursos da FFCL/USP. Apesar de mencionar uma lista de nacionalidades dos professores - "Tivemos professores franceses, professores italianos, professores alemães, professores portugueses" (Freitas, 1992, p. 189) - é aos franceses que o entrevistado costuma recorrer em outros momentos de suas reminiscências em sua fala sobre o corpo de professores:

Sonia Freitas: O senhor acredita que houve empobrecimento de conteúdo e rigor metodológico com a partida de boa parte de professores estrangeiros da Faculdade? Eduardo d'Oliveira França: Dos professores que nos vieram, muitos deles eram ainda professores de Liceu [...]. Eram agrégés que se haviam destacado nos con- 
cursos para o magistério secundário na França, concursos muito duros. (Freitas, 1992, p. 189)

Essa novidade dos professores estrangeiros é ainda mais acentuada na contraposição aos professores das cadeiras de história do Brasil. Sobre o que considera a baixa contribuição da FFCL ao ensino e à pesquisa em história, após atribuir a si parte do problema, já que como professor de moderna e contemporânea não se enveredou pela história do Brasil, França associa a inércia aos professores nacionais já consagrados que ocuparam essa cadeira.

Fico pensando por que isso aconteceu, e me parece que talvez pelo fato de a História do Brasil, cadeira-chave - falo ainda de cadeira, porque havia cátedras naquele tempo -, ter sido entregue a nacionais que já possuíam posições historiográficas definidas. Nacionais de renome, de mérito, Taunay, como o Alfredo Ellis, que já não estavam disponíveis para rever os seus comportamentos no campo da pesquisa histórica. Permaneceu uma espécie de inércia da produção historiográfica no campo da História do Brasil. Há erros que têm consequências. (Freitas, 1992, p. 200)

O raciocínio do professor é bastante longo. Ele continua sua interpretação e foca-se principalmente no que aqueles de "seu grupo" poderiam ter feito:

Quando Braudel veio para o Brasil, trouxe programas que pretendia desenvolver aqui, e entre eles um programa que era de História do Brasil, História do Brasil do século XVI. Houve uma reação contra. Um nacionalismo infantil reclamava que viessem professores do estrangeiro ensinar História do Brasil aos brasileiros. O que era uma visão positivamente primária. Então, achou-se mais político que Braudel não desse aquele curso de História do Brasil. (Freitas, 1992, p. 200)

Essa visão contém algumas chaves explicativas que se perpetuam nas análises da historiografia na USP: a polarização franceses vs. brasileiros, a baixa produtividade da cadeira de história do Brasil e a certeza da influência dos Annales na produção uspiana.

Maria Helena Capelato, Raquel Glézer e Vera Ferlini, em texto que inscreveu a expressão "Escola Uspiana de História" na história da historiografia brasileira, buscaram traçar uma genealogia da produção em história oriunda da instituição. Ao longo do texto, fica clara a demarcação desse desenvolvimento a partir da vinda de professores estrangeiros para o Departamento de História. 
No plano intelectual, os franceses introduziram a preocupação com a orientação metodológica e com o rigor da análise documental, iniciando uma relação com temas da historiografia francesa, especialmente a dos Annales, vanguarda na época. (Capelato; Ferlini; Glézer, 1994, p. 351)

Percebe-se que além do caráter de iniciação neste começo de curso de história, ("introduziram a preocupação com a orientação metodológica e com o rigor da análise documental”) há também um juízo de valor atribuído a essa influência, uma vez que os Annales seriam "vanguarda na época". Ao longo do texto, permanece a interpretação balizada pela presença ou não dos Annales, como nos seguintes trechos:

Esse primeiro conjunto da produção, a dos formadores, não é homogêneo. Se, por um lado, a matriz francesa estimulou as pesquisas nas áreas de História Antiga, História Medieval, História Moderna e História da América, por outro, a presença de Alfredo Ellis Jr. com formação na tradição historiográfica brasileira, radicada em Capistrano de Abreu, teve peso nos estudos de História do Brasil. (Idem, p. 352)

Do ponto de vista metodológico, a influência dos Annales persistiu. Mas não se tratava apenas de continuidade, pois a incorporação de reflexões de natureza marxista representou mudança significativa nas pesquisas. (Capelato; Ferlini; Glézer, 1994, p. 353)

As considerações sobre a história do curso de história e os primórdios da historiografia universitária brasileira das três autoras não são as únicas. O que se percebe em algumas dessas narrativas sobre essa história é que, assim como nas memórias, há uma correlação automática da influência dos franceses no desenvolvimento da subsequente historiografia universitária paulista: isto é, os franceses estiveram aqui, eles nos influenciaram. Braudel é utilizado até mesmo para demarcar o nascimento de um Sérgio Buarque de Holanda: "Nascido em São Paulo, em 1902, mesmo ano de nascimento de Fernand Braudel, Sérgio Buarque mudou-se para o Rio de Janeiro [...]" (Tengarrinha; Arruda, 1999, p. 46).

Na citada obra de Tengarrinha e Arruda, diz-se que: "Lucien Febvre já havia prenunciado que a América Latina era um campo privilegiado para os estudos históricos no número inaugural da revista Annales em 1929. O vaticínio se cumpre com a chegada da missão francesa." (Tengarrinha; Arruda, 1999, p. 50). Encontra-se aí quase uma aura de destino manifesto. Confundindo 
consequência com causa e como se a ligação entre os Annales e São Paulo já estivesse prescrita, não se menciona que a vinda de professores franceses ao Brasil é fruto de uma missão diplomática, altamente interessada, do governo francês. Ou seja, não era exatamente um projeto profissional para esses professores ou um projeto dos Annales em particular, muito menos entre os anos de 1935-1946, mas uma atividade a mais em que se engajaram, mantendo por vezes suas ocupações profissionais na França.

De qualquer forma, é preciso lembrar o caráter ensaístico desta análise, e talvez por isso mesmo não se pode deixar de apontar que condensa uma argumentação frequentemente usada para explicar a influência dos Annales no curso de história e geografia da USP. Esse mesmo texto incorre ainda em duas outras lógicas. A primeira, no afã de destacar o sopro de inovação e pioneirismo que Braudel teria trazido a São Paulo, junta a produção de seus professores num continuum orientado pela batuta, obviamente de Braudel:

Os resultados não se fizeram esperar. Em São Paulo, no Departamento de História da USP, onde Fernand Braudel sistematizou suas pesquisas que resultariam no clássico O Mediterrâneo, ainda numa linhagem atrelada a Capistrano de Abreu e Alfredo Taunay, Alfredo Ellis Jr. defendeu sua tese de doutoramento intitulada Capítulos de História Social de São Paulo, ${ }^{2}$ em 1939, a primeira tese defendida na área de humanidades da Faculdade de Filosofia. (Tengarrinha; Arruda, 1999, p. 50)

A ligação estabelecida entre a defesa de cátedra de Ellis Jr. e a presença de Braudel num mesmo parágrafo ignorou o fato de que Ellis Jr. passou pela banca para manter sua vaga na Faculdade (por contrato, passados dois anos eles precisariam defender tese para continuar como professores). Não há indícios de que a defesa dele tenha sido inspirada pelo ambiente criado pela sistematização da pesquisa de O Mediterrâneo, ou que a atuação de Ellis Jr. e Braudel tenha exercido impacto um sobre o outro a fim de construir algo coletivo para o curso. Na verdade, Braudel parece ser utilizado como selo de qualidade num parágrafo sobre a defesa de Ellis Jr.

Outro movimento que se percebe nesse tipo de afirmação é o esforço que se faz para conferir algum tipo de significado especial em sua vida à passagem de Braudel pelo Brasil. Isso se faz via de regra lembrando que foi nesses anos que Braudel "sistematizou suas pesquisas" para O Mediterrâneo. Nesse caso, Tengarrinha e Arruda são acompanhados de Luis Corrêa Lima, cuja tese se dedica à experiência de Braudel no Brasil e à influência que o país possa ter 
tido no desenvolvimento da obra dele. O quarto capítulo, "O Brasil transforma Braudel", é o exemplo mais representativo de seu objetivo: "Portanto, pode-se concluir: foi no Brasil, e de certo modo com a ajuda dos brasileiros, que Braudel se tornou 'o Braudel do Mediterrâneo"' (Lima, 2009, p. 107). Lima termina o capítulo assertivamente: chama o período de 1935 a 1937 como "os anos brasileiros formadores e decisivos."

Outras iniciativas recuperam o significado especial do Brasil na obra de Braudel ao mesmo tempo que relembram o impacto de sua presença para a universidade brasileira, o que parece ser o caso de Roiz (2013):

Foi com esses preceitos que Braudel instruiria as primeiras turmas de alunos do Curso de Geografia e História da FFCL/USP, e que veriam nele o inaugurador da moderna pesquisa histórica na universidade brasileira. Fato marcante que não se explicaria apenas porque Braudel tenha se tornado o grande historiador do século passado, mas também por ter feito na universidade, durante o período em que esteve à frente da cadeira de História das Civilizações, laços de amizades duradouros, com alunos e professores, a exemplo de Eurípedes Simões de Paula, Alice Piffer Canabrava, Eduardo d'Oliveira França e Branca da Cunha Caldeira, com os quais manteve uma considerável correspondência ao longo de sua vida profissional”. (Roiz, 2013, p. 300, grifo nosso)

Ainda que ressalte quanto a efetiva gestão das teorizações de Braudel ocorrerá a partir dos anos 1940 e 1950 (Roiz, 2013, p. 301), essa contrapartida - o fator Braudel para a universidade brasileira - é colocada a partir da voz de uma memória acadêmica. ${ }^{3}$ Fica em aberto neste caso o que de especial ou de diferente em relação ao modus operandi de outros contatos/amizades teria representado essa amizade brasileira para a produção historiográfica de Braudel. O argumento da relevância da amizade com seus alunos talvez seja mais apropriado à importância que isso pode ter tido na vida desses próprios alunos do que na vida de Braudel.

Braudel é, nessas obras, referido a partir da fala ou das memórias de seus ex-alunos, que o colocam como o inaugurador da moderna pesquisa histórica na universidade brasileira pela sua passagem de três anos entre 1935-1937 e depois por alguns meses em 1947. Essa generalização é arriscada, pois desconsidera inclusive as experiências de outras universidades, como as cariocas, a mineira, a paranaense, somente restringindo-se às mais antigas. Além disso, tece uma continuidade ininterrupta entre as produções em pesquisa uspiana com toda aquela do resto do país e coloca a universidade como representativa 
da produção de pesquisa no período, quando ainda coexistem outros lugares que assumem funções que a universidade só vai assumir mais tarde. É uma afirmação que usa Braudel para afirmar a relevância de um curso sobre o resto do país.

Pela tradição única no país, Braudel vira um selo de distinção. Mas como se inaugura uma moderna tradição de pesquisa no Brasil se Braudel sequer se encontrava no país quando as primeiras teses de doutorado foram escritas e defendidas?

\section{POR OUTRO LADO...}

Entre as reflexões que retomam essas questões e as problematizam estão as considerações de Antônio Celso Ferreira, Fernanda Massi, Lidiane Rodrigues, Margarida Oliveira, Marieta Ferreira, Paulo Martinez, Paulo Miceli e Raimundo Barroso, as quais serão trabalhadas aqui naqueles elementos que problematizam a visão de que a historiografia brasileira universitária nasceu sob o signo dos Annales.

Uma hipótese para essa visão de monumentalização dos Annales é justamente um anacronismo com o qual enxergamos o início da trajetória dos cursos de história no país. É um lapso comum que os olhos de hoje busquem nas origens aquilo que é reconhecido como semelhante à prática acadêmica contemporânea, "demarcando o seu terreno em relação aos estudos empreendidos anteriormente, como os do IHGSP, tidos como 'pré-científicos', dos quais era preciso distanciar-se para sua afirmação institucional”, como afirma Antônio Celso Ferreira (2002, p. 174), e aos quais se associam as obras de Taunay, Ayrosa e Ellis Jr., os primeiros professores brasileiros do curso.

Miceli também atenta para as relações de amizade aqui estabelecidas nas reiteradas vezes em que Braudel relembra sua passagem pelo país - na maior parte das vezes em entrevistas dadas a jornais brasileiros, o que nos faz pensar o quanto as falas também não são um sinal de carinho e afago aos interlocutores/leitores -, mas tem cuidado ao apontar como se toma essas relações pessoais por uma transposição imediata de influência sobre a produção historiográfica local. Sem meias palavras, Miceli propõe:

Por essas razões, mais do que refletir sobre as influências da Escola dos Annales no Brasil, parece mais correto considerar, numa relação dialética, as influências no sentido inverso. Por isso, Braudel jamais publicou um livro sobre o Brasil: não estavam aqui os seus problemas e questões, mas apenas e principalmente um 
vasto laboratório para aferição e desenvolvimento de seus conceitos fundamentais, o que pode ferir um pouco o orgulho de alguns de seus "herdeiros", que, aliás, quase nada produziram de significativo, já que não adianta alisar as pedras tocadas pelo historiador, na esperança de apreender o sentido de sua filosofia da História, mesmo porque ela é sobretudo uma história elaborada a partir da experiência - como faziam alguns antigos viajantes -, e experiência é coisa que mais se exibe do que se transmite. (Miceli, 2001, p. 263)

Martinez publicou em 2002 um artigo que propõe algumas notas para estudo sobre esse período inicial do curso de história da USP, do que destacamos sua preocupação em descentrar a análise da figura de Braudel. Muito embora o autor não use exatamente esses termos, isso dá a entender quando indica o mapeamento das relações entre historiadores brasileiros, Braudel e outros mestres franceses; quando propõe que se analise efetivamente nas produções atuais, "com maior rigor e clareza, o raio de ação e repercussão da presença de Fernand Braudel na produção historiográfica nacional e detectar a existência de diálogos teóricos e metodológicos com outros historiadores franceses" e, por fim, que a produção intelectual dessa primeira geração de historiadores formados na USP se torne objeto de análise que tenha uma dimensão de conjunto, de sua trajetória acadêmica e profissional (Martinez, 2002, p. 21-22).

Marieta Ferreira, por sua vez, mesmo que tratando da trajetória dos professores franceses nos cursos do Rio de Janeiro na década de 1930, já em 1999 alertava para o fato de que Braudel era ainda predominantemente um professor de liceu na França quando veio ao Brasil e lembrava que ele ainda não mantinha "[...] contatos mais estreitos com Bloch e Fèbvre e não tivesse publicado nada nos Annales e muito pouco em outros periódicos [...]" (Ferreira, 1999, p. 295). As consequências da abordagem como a que propõe Paulo Martinez, reforçada pelo alerta de Marieta Ferreira, parecem continuar respeitando o impacto da figura de Braudel, mas também abrem espaço para a análise das outras relações que se estabeleceram no período, isto é, uma abordagem de conjunto e também de trajetória, bem como dão margem para distinguir o impacto do Braudel de 1935-1937 daquele de um Braudel a caminho da consagração em 1947. ${ }^{4}$

Lidiane Rodrigues não tomou especificamente a passagem de Fernand Braudel como objeto, mas dedicou uma seção de sua tese sobre o grupo d'O Capital na USP para investigar as relações estabelecidas entre os professores do curso de história e a formação de alunos seus que viriam a participar da- 
quele grupo. Essa passagem foi condensada num artigo para a Revista de História da Historiografia intitulado "Armadilha à francesa: homens sem profissão” (2013), mas é numa resenha sobre o livro As transferências culturais na historiografia brasileira: leituras e apropriações do movimento dos Annales no Brasil, de Diogo Roiz e Jonas Rafael (2014), que a autora deixa ver alguns incômodos no que percebe desse tipo de análise. Rodrigues acredita que as fontes legislativas precisam ser confrontadas com a vivência social e a análise das obras desses sujeitos - fato que a própria autora fez na sua tese de doutorado, atentando para a necessidade de prestar atenção aos laços de solidariedade profissional entre alunos e professores da época. A autora questiona ainda: "Teria sido esse período e por meio de suas aulas e palestras que o programa (total ou parcial, a investigar) dos Annales foi incorporado por seus ouvintes?" (Rodrigues, 2014, p. 196). A dúvida da autora alerta para a importância de distinguir a quem, ao quê e quando precisamos prestar atenção quando se fala em "herança dos Annales", especialmente porque, a partir dos depoimentos de alguns historiadores identificados à própria corrente, a noção mesmo de uma "escola dos Annales" não é totalmente adequada. ${ }^{5}$ Vale lembrar que a VI Seção da Escola Prática de Altos Estudos é fundada somente em 1947, portanto, uma década após a passagem de Braudel por São Paulo (mais exatamente no período de sua segunda passagem), de forma que é preciso tomar cuidado na naturalização da existência de uma corrente dos Annales na década de 1930 e 1940 que já pudesse exercer algum tipo de influência sobre os colegas paulistas. ${ }^{6}$

A pergunta de Rodrigues sobre se o programa dos Annales teria se incorporado em sala de aula vai ao encontro das considerações que Margarida Oliveira oferece ao debater a apropriação que os Parâmetros Curriculares Nacionais, publicados no Brasil em 1996, teriam feito dos pressupostos annalistas. Desnaturalizando a ideia de que por serem renovadores na prática de pesquisa assim o seriam no ensino de história, Oliveira retoma considerações de historiadores frequentemente associados ao próprio movimento, como Braudel, Jacques Le Goff e Emmanuel Le Roy Ladurie, aponta suas reservas à transposição automática dessas renovações para o ensino de história nas escolas, chegando mesmo a defender a manutenção de um trabalho sobre a cronologia histórica como fundamental para os níveis iniciais da educação (Oliveira, 2007). Isso leva a atentar para as distinções que poderiam existir ou não entre a atividade de sala de aula dos primeiros professores franceses na USP e seus pressupostos teórico-metodológicos para a escrita da história. Rodrigues e Oliveira permitem questionar se eram realmente "os Annales" que se ensina- 
vam em sala de aula e a ir um pouco além: se eram (ou não), o que haveria de renovador nessas práticas?

Por fim, Fernanda Massi (1991) e Raimundo Barroso Cordeiro Junior (2000) tecem algumas conclusões acerca daquela que é considerada o principal elo de ligação entre os Annales e uma Escola Uspiana de História: a Revista de História da USP. Para Massi,

Eurípedes S. de Paula, assistente de Braudel, assumiu o papel de porta-voz do grupo dos Annales, ainda que em seus trabalhos tal débito intelectual não apareça. De qualquer modo, o catedrático da cadeira de história antiga e medieval, ao fundar a Revista de História, em 1950, por exemplo, não cansou de proclamar sua inspiração no modelo dos Annales. Não que esta marca não se note, principalmente através da assídua colaboração francesa na publicação. Mas, ao lado dos historiadores franceses, comparecem os representantes da clássica historiografia brasileira, sobretudo em seções como a de "Numismática". Nesse sentido, a revista é expressão das distintas orientações presentas nas cadeiras de história da USP: ao lado dos franceses e dos Annales, a história política, as biografias e os bandeirantes. (Massi, 1991, p. 239-240)

Em suma, poderíamos dizer que a influência do grupo dos Annales, apesar de nos ter sido trazida diretamente pela presença de vários de seus representantes, num momento bastante particular - o da formação da Universidade e das disciplinas acadêmicas - não encontrou o eco esperado na produção local, salvo uma outra exceção. Os Annales, a meu ver, têm maior impacto hoje, resgatados através dos historiadores "das mentalidades", do que nos anos 40, 50 e 60. (Massi, 1991, p. 245)

Raimundo Barroso em tese sobre o projeto historiográfico de Lucien Febvre defendida na Universidade Estadual de Campinas (Unicamp) em 2000 também dedica um tempo para constatar que,

Passados os anos da Segunda Guerra Mundial, é que, então, percebe-se uma aproximação um pouco mais consistente dos historiadores brasileiros com a historiografia dos Annales. Mas ainda não é nada que indique uma adesão definitiva, posto que se trata apenas da introdução ou utilização das obras e da contribuição de alguns historiadores ligados àquele movimento, nas bibliografias dos trabalhos realizados nos programas de pós-graduação. (Cordeiro Junior, 2000, p. 221) 
E ainda, separando as relações pessoais de uma efetiva incorporação dos princípios annalistas:

A euforia contida nos comentários do professor Eurípedes Simões de Paula a respeito de uma provável repercussão do pensamento de Febvre na formação de historiadores brasileiros, provavelmente foi motivada pela dor do falecimento daquele intelectual respeitado. Mas há-de se considerar que, de 1956 até hoje, bem pouco tem se revelado nas obras nacionais para que se considere essa declaração procedente e de fato tenha havido uma recepção de modo a se identificar uma corrente historiográfica febvreana no Brasil. Na verdade, é muito uma declaração de amizade e admiração pessoal do que propriamente o resultado de uma constatação segura. (Cordeiro Junior, 2000, p. 225-226)

Os trabalhos de Rodrigues, Massi e Cordeiro Junior são teses e dissertações sobre história intelectual e/ou história das ciências que se debruçam sobre outros recortes que não a historiografia paulistana universitária - o grupo de estudos sobre O Capital na USP, a missão francesa na universidade e o projeto historiográfico de Febvre, respectivamente -, mas que avançam em cima do que Miceli, Martinez e Oliveira já anunciam, apontando a necessidade de se problematizar a demarcação de periodizações para a historiografia universitária e a separação entre relações pessoais e apropriações acadêmicas. Alguns outros trabalhos, por sua vez, já se debruçaram especificamente sobre esse tema, tendo como dúvida principal o questionamento do tipo de incorporação ocorrida dos Annales no Brasil.

\section{Alguns eXercícios Alternativos...}

Dentre as iniciativas que problematizaram efetivamente a relação entre presença francesa e influência sobre a historiografia universitária paulista, podemos tomar três exemplos de trabalhos já concluídos: Fabrício Alves (2010), Aryana Costa (2018) e Diego Freire (2019).

Alves trabalhou com a primeira década da Revista de História da USP na sua dissertação de mestrado defendida no Programa de Pós-Graduação em História da Universidade Federal da Paraíba em 2010, fazendo uma recuperação de sua composição, comercialização e um levantamento quantitativo de diversos aspectos: origem geográfica e institucional dos autores, recorrência das áreas temáticas por recortes espaciais e temporais, citações de autorias e periódicos, etc. Seu trabalho pautou-se por referências em história dos impres- 
sos, para analisar a materialidade e o lugar social dos dez primeiros anos da Revista de História com o objetivo de compreender um projeto intelectual e editorial que constatou como sendo de legitimação de posições no campo intelectual por meio da apropriação dos Annales.

Alves contabilizou o total de $74,58 \%$ de trabalhos que abordaram temas do conhecimento histórico e historiográfico (2010), o restante pertenceu às demais áreas de conhecimento, como língua e literatura, filosofia, biografia, geografia, etc. Chegou também à conclusão de que os números da localização geográfica dos lugares institucionais dos colaboradores da revista revelaram que "as instituições de saber sediadas na França ficaram atrás somente do estado de São Paulo" (Alves, 2010, p. 98-99).

Ao afunilar seus critérios de quantificação, detendo-se nas referências bibliográficas citadas no período que delimitou, Alves chegou ao montante de “3.546 diferentes autores, das mais diversas nacionalidades" (2010, p. 146). Desse número, os franceses corresponderam a 21,55\% dos autores citados, enquanto as referências brasileiras somaram 18,28\% (Alves, 2010). A partir daqui nos deparamos com uma informação interessante: foi possível "observar que os autores franceses mais citados foram A. Comte, H. Taine, E. Gilson, Saint-Hilaire e H. Harrisse. Respectivamente, seus trabalhos mais mencionados foram: Discours sur l'Esprit Positif, Essai sur Tite-Live, L'Esprit de La Philosophie Médiévale, Viagens à Província de São Paulo e The Discovery of North América" (Alves, 2010, p. 147-148). Além disso, outros nomes clássicos figuraram junto aos annalistas na Revista de História: H. Bergson, E. Bréhier, F. de Coulanges, J. Michelet, Ch. V. Langlois, Ch. Seignobos e E. Lavisse (Alves, 2010).

Sobre as citações a referências nacionais, os dados levantados são igualmente interessantes: Alves constatou que Sérgio Buarque de Holanda, Caio Prado Júnior e Gilberto Freire corresponderam ao maior número de citações (2010). "Capistrano de Abreu, João P. Calógeras, Joaquim Nabuco, R. Teixeira, Sílvio Romero e Oliveira Viana também foram lembrados com frequência, junto com os seus respectivos trabalhos" (Alves, 2010, p. 150). Mas,

dentro de todo esse universo de autores citados, Affonso d'E. Taunay destaca-se por ter sido o mais mencionado, pois o mesmo teve 37 de suas publicações veiculadas enquanto referência. Sua obra mais difundida nas notas foi a História Geral das Bandeiras Paulistas, verdadeiro clássico da historiografia paulista e brasileira. (Alves, 2010, p. 151) 
Sendo assim, Alves pôde desnaturalizar as relações entre os pesquisadores e as instituições ao lembrar os interesses que estavam por trás da aproximação estabelecida por ambas as partes. Por uma parte, historiadores diretores da Revista dos Annales para criar vínculos com uma instituição latino-americana através dos quais pudesse espalhar os seus pressupostos teórico-metodológicos, e por outra parte, os uspianos

para legitimar a produção historiográfica uspiana frente à historiografia elaborada nos Institutos Históricos e nas academias situadas no campo intelectual paulista. Nessas condições, a [Revista de História] foi empregada, sobretudo, para diferenciar o conhecimento histórico universitário daquele elaborado nas instituições de saber tradicionais. (Alves, 2010, p. 193)

E sobre a posterior construção da história da historiografia paulista, o autor conclui que: "[...] a historiografia uspiana mitificou esse contato com os Annales, uma vez que a aproximação com essa concepção historiográfica permitiu-lhe ocupar posições e legitimar práticas no campo intelectual paulista e brasileiro" (Alves, 2010, p. 195).

A tese que defendi no Programa de Pós-Graduação em História Social da Universidade Federal do Rio de Janeiro em 2018 enveredo pelo alerta que Margarida Oliveira faz, atentando para o perfil docente dos professores que vieram ao Brasil lecionar na cadeira de História da Civilização, em especial Fernand Braudel e Jean Gagé. Tomando o currículo do ensino superior como objeto de pesquisa, debrucei-me sobre o encadeamento dos semestres, comparei programas de cursos com seus relatórios e tomei o currículo do ponto de vista do percurso que os alunos faziam, revelando que boa parte do que se disse que foi ministrado ao final das contas - e replicado em obras sobre o período - não foi. Para mim, o início das aulas de História na USP teria sido marcado por professores tateando ainda em seus cursos, com planos e atividades mais bem definidas na cadeira de História da Civilização, por exemplo, somente a partir de 1937. As outras cadeiras duravam ciclos mais curtos de um ano, o que não exigia a continuidade no ano seguinte do curso para a turma. A urgência no segundo ano de existência da faculdade em buscar alunos para os seus quadros, recorrendo ao comissionamento de professores primários e secundários, desnaturaliza a celebrada preocupação dos professores franceses com a formação pedagógica, quase voluntarista. Defendo que isso ajuda a repensar a qualificação das diferenças entre os professores nativos e estrangeiros, 
ou ao dimensionar uma fonte como a palestra de Fernand Braudel sobre Pedagogia da História no próprio Instituto de Educação da USP (IEUSP).

Ao me perguntar sobre os professores Braudel e Gagé, e entendendo que os saberes docentes são construídos ao longo de uma trajetória profissional, na tese são colocadas questões sobre qual metodologia, avaliações e conteúdos eram trabalhados em sala de aula. Afirmo que Braudel e Gagé que se apresentavam na memória perpetuada forneciam uma visão congelada daquele momento, sem nuances. Suas qualidades como professores eram pessoais: simpatia, acessibilidade, domínio do conteúdo. Qualidades inclusive por vezes confundidas com os dotes dos Annales.

Colocá-los em contexto contribuiu para que destrinchasse a palestra de Fernand Braudel no Instituto de Educação, em 1936, sobre Pedagogia da História, vislumbrando também a sua prática de sala de aula, tendo em vista as semelhanças entre a palestra e o seu material didático. Uma tradição interessante que misturava humanismo e Michelet com doses de Seignobos e Lavisse e que não necessariamente correspondia, segundo a autora, a uma aplicação dos Annales nas aulas. Isso acarreta uma pergunta interessante: o quanto dos temas pelos quais os Annales ficaram famosos é original?

Defendo a originalidade da sala de aula do curso de História da USP, porém, em outros termos. Não haveria como negar a qualidade dos professores franceses, especialmente com o que se sabe sobre Jean Gagé pelo relato de seu ex-aluno, Moacyr Campos. O interessante seria perceber que suas virtudes na sala de aula não são decorrentes da Escola dos Annales, que é praticamente o que os dota de qualidade nas lembranças de seus ex-alunos, mas da própria trajetória docente. Identificar isso também ajuda a datar a transmissão, ou melhor, a reprodução dessa influência, que defendo que não ocorreu na década de 1930, apontando para uma consolidação mais efetiva a partir da década de 1950.

Em artigo publicado em 2019, Diego Freire toma como mote para sua problematização a manifestação do Programa de Pós-Graduação em História Econômica da USP, que recorreu à memória disciplinar de descendente de Fernand Braudel como um dos elementos para justificar sua tradição, quando descredenciado pela Coordenação de Aperfeiçoamento de Pessoal de Nível Superior (Capes) em 2017. Enquanto Alves e eu nos debruçamos sobre práticas de editoração e ensino no campo acadêmico para problematizar essas relações, Freire se dedica à análise de um artigo como fonte: o já citado A Escola Uspiana de História. Em sua análise, Diego se debruça sobre marcadores no texto de Capelato, Glezer e Ferlini que atribuem valor e demarcam uma posição para a dita escola na his- 
tória da historiografia brasileira, como a escolha pelas autoras de termos como "Escola”, "geração", "inbreeding", "DNA”, aproximando a tradição uspiana daquela dos Annales por meio da constituição de uma cronologia causal, linear, motivada amplamente por um exercício de memória:

A formulação identitária de uma atividade intelectual imaginada como tipicamente uspiana é tributária de uma visada memorialística. Daí os nexos de continuidade entre passado e presente, a linearidade temporal, o tom afetivo, o senso de pertencimento e de unidade que emergem dessa construção. (Freire, 2019, p. 146)

O autor se propõe ainda a considerar as condições de produção do artigo - o dossiê comemorativo da Estudos Avançados em homenagem aos cinquenta anos da USP, o momento de expansão das pós-graduações em História no país, a posição acadêmica das autoras, além dos desdobramentos de suas premissas em outras publicações.

Alves, Freire e o meu trabalho avançaram por três caminhos diferentes nos alertas para a real dimensão do alcance de uma historiografia francesa na constituição da historiografia universitária brasileira. Até mesmo pelo fato de ser um artigo - enquanto os outros dois trabalhos são uma dissertação e uma tese, é razoável dizer que o trabalho de Freire funciona como um mote inicial, que lança a problematização sobre a constituição de um artigo que periodizou a história da historiografia uspiana. Finda por ser uma sofisticação das inquietações de Franzini, Rodrigues, Barroso, etc., uma interrogação no nível de análise de texto referente a uma periodização à qual Fabricio Alves, por meio da materialidade e da quantificação na Revista de História, e meu trabalho, por meio da organização curricular e das práticas de ensino, tentam responder. São abordagens que se complementam - práticas de construção de texto e de constituição de campo - e que têm servido para: reforçar o cuidado com o caráter monumentalizador em que uma história da historiografia pode incorrer, repensar a periodização da história da historiografia brasileira e forçar a abertura para abordagens metodológicas que deem conta de formular novas perguntas.

\section{UMA FONTE PARA APLACAR OS DESEJOS:}

UMA HISTÓRIA DO BRASIL PROPOSTA POR BRAUDEL ${ }^{7}$

Retomemos, por fim, um dos motes que alimentaram a tradição dos Annales no Brasil: a presença de um Brasil no Braudel e vice-versa. Isto é: a dife- 
rença que o Brasil teria feito na trajetória braudeliana e o quanto ele poderia ter contribuído para a modernização da historiografia nacional sobre o Brasil.

Trago a possibilidade de análise de um novo elemento para essa questão. Entre a documentação arquivada na Fondation Maison des Sciences de l'Homme (FMSH), no acervo concernente a Fernand Braudel, encontram-se, afinal, anotações de um possível livro sobre o Brasil. Assim, abre-se caminho para enveredar por outros e novos percursos, além de tentar escavacar na biografia do francês ou na composição do Mediterrâneo aquilo que seria comprovadamente tributário da sua estadia por aqui.

Não há datas nos documentos encontrados, mas a partir de algumas anotações à mão que incluem os nomes de ex-alunos brasileiros e dos recortes de jornais datados da década de 1930 que acompanham esses rascunhos, podemos pressupor que sejam do período em que Braudel esteve pelo Brasil. Escreve ele que: "Si j'écris un livre sur le Brèsil, l'organiser dans ses cadres politiques sous forme d'un récit expliqué. Premiere partie: la 1er age colonial. Deuxième partie: la second âge coloniale (le XVIIIe). Troisieme partie: l'empire. Quatrieme partie: les Republiques 1889-19..." (FMSH, Cote 4A1, boîte 38)

Em outra anotação, encontra-se o seguinte sumário:

\section{Livre sur le Brésil}

Mon livre, si livre il soit, $j$ 'avais sur le Brèsil.

Livre I: le premier age colonial. XVI et XVII avec comme sous titre: le Brèsil sera-t-il portugais?

Livre II: la second âge colonial. Le XVIIIes.

Livre III: le Brèsil sera-t-il independant? 1807-1822 en sous titre les origines de l'Empire.

Livre IV: Grandeur et fragilité de l'Empire 1822-1889.

Livre V: Les Republiques: le Brésil sera-t-il une grande puissance?

Détail du livre I:

Chapitre I: les cadres geographiques.

Chapitre II: Les Pré-Brésils.

Chapitre III: Les découvertes maritimes du début du XVIes. Chapitre IV: la guerre pour le "pau-brasil".

Chapitre V: la canne à sucre, victoire portugaise.

Chapitre VI: les (....) sur l'Atlantique 1590-18.... et la poussée des bandeiras.

Chapitre VII: les holandais au Brèsil.

Chapitre VIII: bilan des deux premieres siecles: la civilizations des casas grandes, les premieres villes, la (...) de l'interieur. 
Livre II: les raisons de la prosperité.

Chapitre I: l'Atlantique aux XVIIIes.

Chapitre II: l'or de Minas Gerais.

Chapitre III: le splandeur de Bahia.

Chapitre IV: la (...) de conquête portugaise.

Chapitre V: Mules, tropeiros e toperias. ${ }^{9}$ (FMSH, Cote 4A1/90. boîte 38)

E ainda uma espécie de plano de trabalho e pesquisa que distribui entre ex-alunos e colegas de trabalho as temáticas a que cada um, aparentemente, se especializaria: ${ }^{10}$

I a) pesquizar: (d. Branca)

dados sobre a geographia do paiz:

a) a latérite - terra roxa

b) minéralogia brasileira

c) comprimento dos caminhos antigos (?)

d) velocidades das bandeiras (bandeiras, roteiros. v. sertanistas, bahianos)

e) chronologia (Taunay)

1 - o caminho do Mar: comprimento e differentes nomes estradas

2 - o caminho do Rio de Janeiro - data e demais detalhes - Marambaia, etc. (v. art. "Jornal Commercio")

3 - o desastre da capitania do Espírito Santos - detalhes (?) (documentos portugueses?)

5 - Os engenhos (a cultura da canna de assucar - tudo o que disser respeito a este assumpto - (Antonil - da cult. e opulencia do Brasil).

6 - Assignalar todos os logares onde há "passa-três", "passa-quatro", etc. O mesmo para o que diz respeito a Curral, e outras denominações semelhantes, indicadoras do caminho do gato (Capistrano - "Capítulos").

II (Eurípedes Simões de Paula)

O indígena (v. trabalho Dr. H. Baldus)

Bibliographia actual - situação actual e do século XVII (Lèry, Thevet, Barleu, etc.) O sal gemma no Brasil (?)

III (Cruz Costa)

Portugal no século XVI - o problema negro antes do Brasil (Rosendo Garcia) O judeu - O jesuíta $(v . I V e$ V) 
IV (Eurípedes Simões de Paula)

O frances

O italiano

O espanhol

O hollandes

$\mathrm{O}$ ingles

O judeu

$\mathrm{Na}$ "aventura" do descobrimento e nos séculos XVI e XVII no Brasil.

V (Cruz Costa)

A política do jesuíta

VI (Eurípedes Simões de Paula)

Dados sobre as ilhas do Atlantico: Assores, Madeira, Cabo Verde, Canárias, etc. A África Portuguesa

VII (Eurípedes Simões de Paula)

As Costas do Brasil

VIII (Cruz Costa)

Navios, caravellas, etc. As equipagens, etc.

IX (Cruz Costa)

As etapas do XVI século do Brasil

a) As névoas do princípio do século

c) as rotas oceânicas (Pereira e Hist. Col. Brasil)

d) as descobertas (H. Col. Brasil e B.H. Almeida Prado + (....) Hist. G. Brasil)

c) a história do meridiano (.... Leite e H. Col. Brasil).

X (Eurípedes Simões de Paula)

A Grandeza do "pau brasil” (1550-1560 sobretudo)

Iconographia antiga

Os preços do "pau Brasil"

O milho

O transporte do pau brasil (Lery?)

(Cartas de Anchieta etc. Roteiro - (...) obras séc. XVIII). 
XI (Mello)

A canna de assucar e o triumpho portuguez

O preço do assucar e as sociedades (?) que o exploraram

XII (d. Branca)

Bandeiras (Taunay e J. H. Bahia, Pernambuco, Minas, etc.).

(FMSH, Cote $4 \mathrm{~A} 1 / 90$, boite 38 )

O que se percebe dos recortes guardados nessa caixa é que Braudel colecionava artigos sobre história, geografia e economia do Brasil. Encontram-se vários recortes de artigos de Taunay, do Jornal do Commercio, O Estado de S. Paulo, Afonso Arinos de Melo Franco, Victor Vianna, Monteiro Lobato, Carlos Lacerda, Plínio Barreto (deste, uma resenha sobre Sobrados e Mocambos, de Gilberto Freyre) e sobre agricultura (algodão, milho, cacau, indústria têxtil, café, carne, tabaco).

Suas anotações indicam que se trata de uma abordagem que ainda mantém a história do Brasil dividida em recortes políticos, mas que se pauta por uma discussão da ocupação territorial norteada pelas atividades econômicas; do domínio da natureza pela ação humana. As anotações para pesquisa indicam o uso de Taunay, assim como de bibliografia clássica (Anchieta, Antonil, Capistrano, etc.).

O livro seria resultado de um trabalho coletivo, já que previa a colaboração de Cruz Costa, Branca Caldeira e Eurípedes Simões de Paula e fica como indicação dos quadros que Braudel previa para a organização da história do Brasil.

\section{Possibilidades...}

Diante de um recorte tão ímpar, pois que frequentemente o início dos cursos universitários no Brasil foram considerados um marco na história da historiografia nacional (vide as obras de Capelato et al. e Tengarrinha e Arruda citadas anteriormente), é prudente reanalisar as fontes utilizadas como embasamento para o desenho de uma "escola uspiana de História", que supostamente se originou assim. A começar pela construção de determinados argumentos oriundos de testemunhos e incorporados como explicações de causalidade para a trajetória da historiografia nacional, como a do atraso na produção universitária de história do Brasil, a exemplo dos depoimentos de 
Eduardo d'Oliveira França repercutidos no artigo "A escola uspiana de História” e conforme indicado aqui pelo artigo de Diego Freire.

Trabalhar com testemunhos tem sido um dos principais recursos para escrever uma história dos cursos de graduação, refletindo também na historiografia praticada por esses cursos. Tendo em vista a natureza dessas fontes, deve-se levar em consideração fatores, como disputas acadêmicas, sob pena de que a narrativa construída sobre a história de um curso, as qualidades de um ou outro grupo - como no caso da USP, aquele ligado à Escola dos Annales-, transformem-se quase em um destino manifesto, numa teleologia, na qual uma influência estrangeira como a francesa não tinha outra opção senão a de inevitavelmente se reproduzir, se multiplicar, apenas pelo fato de ter vindo ao Brasil ou porque é naturalmente melhor, mais sofisticada. Filiações teóricas são explicadas por laços de amizade o que, sim, ocorre, mas que deixa de lado, porque assim é a memória, as ações dispensadas para construir e reforçar intencionalmente esses laços. Vê-se, todavia, que já há um conjunto considerável de trabalhos que questionam as explicações para essa causalidade e desnaturalizam essas ações, seja indicando caminhos (como Franzini, Rodrigues, Miceli, Oliveira, Antônio Ferreira, Marieta Ferreira, Massi e Cardoso), seja investindo nisso como uma problemática própria (como Alves, Costa, e Fernandes).

Esses trabalhos contribuem para a discussão metodológica dentro da história da historiografia propondo, para além dos testemunhos e do trabalho sobre o texto de obras historiográficas, caminhos como o trabalho com fontes de sala de aula, constituição de redes acadêmicas, análise de discurso, análises das referências a que se recorre nas introduções ou fundamentações teórico-metodológicas de teses e dissertações, organização de eventos acadêmicos, descendências nas linhas de orientações, etc.

O exemplo do recorte aqui tratado indica que mesmo em se tratando de uma história sobre nossa própria atuação e formação, não estamos isentos de projeções anacrônicas sobre esse passado. Há que se levar em conta as características próprias de um campo acadêmico que se encontrava em vias de criação e organização para que de fato possa ser incorporado como um marco na periodização da historiografia brasileira. Seja a partir de novas fontes, como as das aulas universitárias de História, do IHGSP ou o livro de Fernand Braudel, ou de novas perguntas a velhas fontes, a história da historiografia tem mostrado que possibilidades não faltam para isso. 


\section{FONTES E REFERÊNCIAS BIBLIOGRÁFICAS}

ALVES, Fabrício. Folheando páginas, descobrindo histórias: a Revista de História e a difusão da historiografia dos Annales no Brasil (1950-1960). 2010. Dissertação (Mestrado em História) - Centro de Ciências Humanas, Letras e Artes, Universidade Federal da Paraíba, João Pessoa, 2010.

CAMARGO, Aspásia. O Historiador e a História (um relato de François Furet). Revista Estudos Históricos, Rio de Janeiro, v. 1, n. 1, p. 143-161, 1988.

CAPELATO, Maria Helena; GLÉZER, Raquel; FERLINI, Vera. Escola Uspiana de História. Estudos Avançados, São Paulo, v. 8, n. 22, p. 349-358, 1994.

CORDEIRO JUNIOR, Raimundo. Lucien Febvre: combates por uma nova História. Considerações sobre um projeto historiográfico. 2000. Tese (Doutorado em História) - Instituto de Filosofia e Ciências Humanas, Universidade Estadual de Campinas, Campinas, 2000.

COSTA, Aryana. De um Curso d'água a Outro: memória e disciplinarização do saber histórico na formação dos primeiros professores no curso de História da USP. 2018. Tese (Doutorado em História) - Instituto de História, Universidade Federal do Rio de Janeiro, Rio de Janeiro, 2018.

FRANÇA, Eduardo d'Oliveira. Depoimentos/ homenagens e/ou Trabalhos sobre E.O.F. 12-OS. [Entrevista cedida ao] Centro de Apoio à Pesquisa Histórica. Faculdade de Filosofia, Letras e Ciências Humanas, São Paulo, 1990.

FERREIRA, Antônio Celso. A Epopeia Bandeirante: letrados, instituições, invenção histórica (1870-1940). São Paulo: Editora Unesp, 2002.

FERREIRA, Marieta. Os Professores Franceses e o Ensino da História no Rio de Janeiro nos Anos 30. In: MAIO, Marcos Chor; VILLAS BÔAS, Glaucia (orgs.). Ideias de Modernidade e Sociologia no Brasil: ensaios sobre Luiz Costa Pinto. Porto Alegre: Editora UFRGS, 1999. p. 277-300.

FREIRE, Diego. Memória, História e Identidade: o caso da "escola uspiana de História". Revista ArtCultura, Uberlândia, v. 21, n. 39, p. 139-153, 2019.

FREITAS, Sônia. Reminiscências. Contribuição à Memória da FFCL/USP 1934-1954. São Paulo: Editora Maltese, 1992.

FONDATION MAISON DES SCIENCES DE L'HOMME (France). Fonds Fernand Braudel. Paris, 1963.

FURET, François. A Oficina da História. Lisboa: Editora Gradiva, 1986.

LE GOFF, Jacques. A História Nova. São Paulo: Editora Martins Fontes, 1990.

LIMA, Luis Corrêa. Fernand Braudel e o Brasil. Vivência e Brasilianismo (1935-1945). São Paulo, EDUSP, 2009.

MARTINEZ, Paulo. Fernand Braudel e a Primeira Geração de Historiadores Universitários da USP (1935-1956). Revista de História, São Paulo, n. 146, p. 11- 27, 2002. 
MASSI, Fernanda Peixoto. Estrangeiros no Brasil: a Missão Francesa na Universidade de São Paulo. 1991. Dissertação (Mestrado em Antropologia) Instituto de Filosofia e Ciências Humanas, Universidade Estadual de Campinas, Campinas, 1991.

MICELI, Paulo. Sobre História, Braudel e os Vaga-lumes. A Escola dos Annales e o Brasil (ou vice-versa). In: FREITAS, Marcos (org.). Historiografia Brasileira em Perspectiva. São Paulo: Editora Contexto, 2001. p. 259-270.

OLIVEIRA, Margarida. Parâmetros Curriculares Nacionais: suas ideias sobre História. In: OLIVEIRA, Margarida; STAMATTO, Maria Inês (orgs.). O Livro Didático de História: políticas educacionais, pesquisas e ensino. Natal: EDUFRN, 2007. p. 9-18. PAUL, Herman. Self-Images of the Historical Profession: Idealized Practices and Myths of Origin. Storia della Storiografia, Roma, n. 59-60, 2011. p. 157-170

RODRIGUES, Lidiane. A Produção Social do Marxismo Universitário em São Paulo: Mestres, Discípulos e um Seminário (1958-1978). 2012. Tese (Doutorado em História) - Faculdade de Filosofia, Letras e Ciências Humanas, Universidade de São Paulo. São Paulo, 2012.

RODRIGUES, Lidiane. Armadilha à Francesa: homens sem profissão. História da Historiografia, Ouro Preto, v. 6, n. 11, p. 85-103, 2013.

RODRIGUES, Lidiane. Os Annales e Nós. História da Historiografia, Ouro Preto, v. 7, n. 15, p. 192-198, 2014.

ROIZ, Diogo. Fernand Braudel (1902-1985). In: BENTIVOGLIO, Julio; LOPES, Marcos Antônio (orgs.). A Constituição da História como Ciência: de Ranke a Braudel. Petrópolis: Editora Vozes, 2013. p. 285-316.

ROIZ, Diogo; SANTOS, Jonas. As Transferências Culturais na Historiografia Brasileira: leituras e apropriações do movimento dos Annales no Brasil. Jundiaí: Paco Editorial, 2012.

TENGARRINHA, José Manuel; ARRUDA, José Jobson Arruda. Historiografia Luso-Brasileira contemporânea. Bauru: Edusc, 1999.

\section{NOTAS}

${ }^{1}$ Their self-images show us how they conceived of historical studies, how they taught others to become good historians, what sort of models or examples they admired, and how they positioned themselves in historical trajectories that often served as myths of origin, that is, as master narratives legitimizing their preferred view of historical studies (Paul, 2011, p. 159). "Suas autoimagens nos mostram como eles concebiam os estudos históricos, como eles ensinavam outros a tornarem-se bons historiadores, que sorte de modelos ou exemplos eles admiravam, e como eles se posicionavam em trajetórias históricas que serviam frequentemente como mitos de origem, ou seja, como narrativas principais legitimizadoras da sua visão preferida dos estudos históricos." 
${ }^{2}$ Aqui provavelmente se trata de Afonso Taunay, primeiro professor da cátedra de História da Civilização Brasileira no curso, que também havia sido aluno de Capistrano e contemporâneo de Alfredo Ellis Jr. Alfredo Taunay é seu pai.

${ }^{3} \mathrm{O}$ autor elabora um pouco mais as trocas entre Brasil e França no livro As Transferências Culturais na Historiografia Brasileira (2012).

${ }^{4}$ Reproduzo a seguir o trecho completo dessas últimas duas sugestões: "Em segundo lugar, o esclarecimento das influências teóricas e metodológicas da moderna historiografia francesa nos estudos históricos realizados em São Paulo. (...) Este exame permite demarcar, com maior rigor e clareza, o raio de ação e repercussão da presença de Fernand Braudel na produção historiográfica nacional e detectar a existência de diálogos teóricos e metodológicos com outros historiadores franceses. (...) Torna-se, então, imperativo reunir maiores elementos sobre a passagem da missão francesa na USP e a presença de Braudel no Brasil, em particular, inclusive no breve período em que esteve no país pela segunda vez, entre maio e dezembro de 1947. A notoriedade adquirida posteriormente chama a atenção para esta experiência intelectual dos historiadores franceses no Brasil” (Martinez, 2002, p. 21)

${ }^{5}$ Para ficar somente em depoimentos pessoais como fontes a respeito dessa "des"homogeneização dos Annales, no final da década de 1980, Le Goff argumenta que "formando um meio amplo e aberto, não tendo sequer formado no passado, uma verdadeira 'escola' (é um espírito, uma orientação, uma tendência), eles (os Annales) teriam grande dificuldade para se transformarem em lobby." (1990, p. 4) François Furet repisa a não homogeneidade dos Annales: "A bem dizer, não existe, desde a origem, escola de pensamento: poder-se ia procurar, mas em vão os vestígios de uma doutrina, ou um tipo de explicação, nos Annales antes da guerra." (1986, p. 10). Sobre essa questão, conferir ainda a entrevista de Furet a Aspásia Camargo (1988).

${ }^{6}$ O próprio Roiz, junto com Santos (2012), dedica o primeiro capítulo de seu livro para debater a construção a posteriori de uma narrativa unificadora sobre a história de uma Escola dos Annales.

${ }^{7}$ Mesmo que abreviadamente diante do pouco conhecimento sobre a fonte optei por incluí-la neste artigo para fins de sua publicização.

8 "Se eu escrevesse um livro sobre a história do Brasil, organizaria sob a forma de um relato explicado. Primeira parte: período colonial. Segunda parte: período colonial (século 18). Terceira parte: o império. Quarta parte: as Repúblicas (1889-19...)” (FMSH, Cote 4A1, boîte 38; tradução nossa).

9 "Livro sobre o Brasil. Meu livro, se for livro, que eu tenho sobre o Brasil. Livro 1: a primeira época colonial. XVI e XII com subtítulo: será o Brasil português? Livro II: a segunda época colonial. O XVIII. Livro III: será o Brasil independente? 1807-1822 e como subtítulo as origens do Império. Livro IV: grandeza e fragilidade do Império 1822-1889. Livro V: as repúblicas: será o Brasil uma grande potência? Detalhe do Livro I: capítulo 1: quadros geográficos; capítulo 2: os pré-Brasis; capítulo 3: as descobertas marítimas do início do XVI; capítulo 4: a guerra pelo pau-brasil; capítulo 5: a cana-de-açúcar, vitória portuguesa; capítulo VI: os (...) sobre o Atlântico 1590-18... e o crescimento das bandeiras; capítulo 7: os 
holandeses no Brasil; capítulo 8: balanço dos dois primeiros séculos: a civilização das casas grandes, as primeiras cidades, a (...) do interior. Livro II: as razões da prosperidade. Capítulo 1: o Atlântico no XVIII; Capítulo 2: o ouro de Minas Gerais; capítulo 3: o esplendor da Bahia; capítulo 4: a (...) da conquista portuguesa; capítulo 5: mulas, tropeiros e toperias." (FMSH, Cote 4A1/90. boîte 38; tradução nossa).

${ }^{10} \mathrm{O}$ documento original está datilografado, mas as palavras e frases entre parênteses e em itálico reproduzidas nesta citação encontram-se anotadas à mão no original, numa caligrafia que não parece ser a de Fernand Braudel. Mantive a grafia original. 